\title{
BIBLIOMETRIA DO ACERVO ENANCIB (1994 A 2018)
}

1Marcelo Maia

2Denise Fukumi Tsunoda

Universidade Federal do Paraná1,2

\section{Correspondência}

Marcelo Maia

Universidade Federal do Paraná

Curitiba, PR - Brasil

E-mail: maiamarcelomaia@hotmail.com

(iDORCID: https://orcid.org/0000-0002-2924-4426

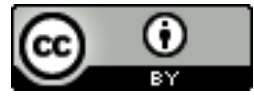

JITA: BB. Bibliometric methods

e-Location: 019038 


\title{
RESUMO
}

Um dos maiores eventos de pesquisa e de pós-graduação da área de Ciência da Informação do país. Sendo assim o objetivo desse trabalho mapear a produção científica por meios de análises bibliométricas, caracterizando o Enancib a partir dos trabalhos publicados nas páginas dos eventos, compreendendo as 19 edições até o momento, absorvendo os grupos de trabalhos. O corpus de estudo foi composto de 4.282 publicações no evento, inserido e processado no software Microsoft Excel, gerando informação de frequência e número de itens publicados dos autores e coautores mais produtivos, posição de autoria dos autores mais produtivos, sendo estes separados, por edição e por grupo de trabalho. O estudo permite verificar a trajetória da existência do Encontro Nacional de Pesquisa em Ciência da Informação, quanto aos componentes: publicações, autores e coautores mais produtivos por edição, grupo de trabalho e na totalidade do evento, 24 anos. A pesquisa revelou que o fato de o autor estar no primeiro lugar, como o autor mais produtivo do evento das edições analisadas, não significa que este seja o mais produtivo por edição e também por grupo de trabalho. Também revelou, o quantitativo de autores em cada grupo de trabalho, edição, demonstrando que a área de ciência da informação está em constante crescimento.

\section{PALAVRAS-CHAVE}

Lei de Lotka; Autores; Coautores; Enancib.

\begin{abstract}
One of the largest research and postgraduate events in the Information Science area in the country. Therefore, the goal of this paper is to map the scientific production through bibliometric analysis, characterizing Enancib from the works published on the events' pages, comprising the 19 editions so far, absorbing the works' groups. The corpus of study was composed of 4,282 publications in the event, inserted and processed in Microsoft Excel software, generating frequency information and number of published items of the most productive authors and co-authors, author position of the most productive authors, these separated by edition, and by working group. The study aides the verification of the trajectory of the existence of the National Meeting of Research in Information Science, as for the components:most productive publications, authors and co-authors for editing, working group and the entire event, 24 years. The research revealed that the fact that the author is in the first place, as the most productive author of the event of the analyzed editions, does not mean that the author is the most productive by edition and also by work group. Also revealed the number of authors in each working group, edition, demonstrating that the area of information science is constantly growing.
\end{abstract}

\section{KEYWORDS}

Lotka's Law; Authors; Co-authors; Enancib. 


\section{Introdução}

O estudo da "mediação da informação tem se expandido no campo da Ciência da Informação, impulsionado pelo interesse em compreender o que condiciona e a movimenta, o que caracteriza e dá forma, quem participa" (FIALHO, NUNES; CARVALHO, 2017, p.253). Assim a produção acadêmica, publicada em eventos, encontros e congressos, apresenta numerosos autores, a que compete aos pesquisadores "decidir [...] qual a ordem em que seus nomes deverão ser nela disposto" (MONTENEGRO; ALVES, 1997, p.273), que implica na "contagem da literatura produzida: contagem direta, contagem completa e contagem fracionada” (URBIZAGASTEGUI, 2008, p.87).

Uma forma de verificar a produtividade e a memória de diversos estudos no campo do conhecimento é a pesquisa bibliométrica, que apresenta um eixo de pesquisa central, que é a produtividade de autores (URBIZAGASTEGUI, 2008). Mapear a produção científica "por meio de análises quantitativas e qualitativas é contribuir para a constituição de um campo científico mais fortalecido, [...] uma vez que os periódicos científicos constituem canais representativos de disseminação e socialização do conhecimento científico" (EVEDOVE; FUJITA; TARTAROTTI, 2013, p.2).

Neste contexto, o evento em pauta é o Encontro Nacional de Pesquisa em Ciência da Informação (ENANCIB) desde a primeira edição (1994) a décima nona (2019), voltado a elementos da bibliometria. Os autores Santos; Reis, Dumont (2018), Fialho; Nunes e Carvalho (2017), Tartarotti; Fujita (2016), Castro; Oliveira (2016), Moreira; Moraes (2016), Evedove; Fujita; Tartarotti (2013); também realizaram estudos sobre a trajetória do Enancib, mas com enfoque diferente. Os autores Santos; Reis, Dumont (2018) descrevem a analise do perfil das pesquisas que envolve a leitura enquanto prática social a partir da bibliometria, Fialho; Nunes e Carvalho (2017) analisam a relação entre a produção científica no GT3 dos ENANCIB e os grupos de pesquisa sobre mediação do CNPq, Tartarotti; Fujita (2016) caracteriza a comunidade científica brasileira a partir da publicação de trabalhos no GT2 no período de 2009 a 2014 com a utilização de indicadores bibliométricos de produção e ligação. Já Castro; Oliveira (2016) analisam a produção nos períodos de 2012 a 2015 sobre a linguagem de indexação, Moreira; Moraes (2016) descreve a temática de como a classificação tem sido abordada na ciência da informação brasileira, identificando os pesquisadores mais produtivos entre 2003 e 2014, e Evedove; Fujita; Tartarotti (2013) caracteriza a comunidade científica brasileira na temática indexação a partir dos artigos no período de 2003 a 2012 por meio de indicadores bibliométricos.

Desse modo, o objetivo é mapear a produção científica por meios de análises bibliométricas, caracterizando o Enancib a partir dos trabalhos publicados nas páginas dos eventos, compreendendo as 19 edições até o momento, absorvendo os grupos de trabalhos. A

v.17

$1-21$

e019038
2019 


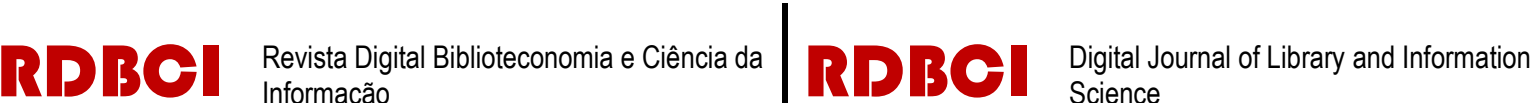

separação em grupos de trabalho "propicia a visualização de parâmetros que tornam possível avaliar e repensar seus objetivos e dá subsídios para tomadas de decisões que viabilizem uma reprogramação das suas estratégias de crescimentos" (GRÁCIO; OLIVEIRA, 2010, p.3), sendo que os grupos, expressam "medição, mapeamento, diagnóstico e avaliação da informação nos processos de produção, armazenamento, comunicação e uso, em ciência, tecnologia e inovação" (GRÁCIO; OLIVEIRA, 2010, p.2).

Justifica-se o presente estudo, pela ausência na exploração da aplicação da lei de Lotka (URBIZAGASTEGUI, 2008), de tal forma que o "modelo tem se convertido no eixo central da pesquisa bibliométrica contemporânea [...] tais como artigos periódicos, capítulos de livros, trabalhos apresentados em congressos e similares canais de informação capazes de tornar públicos os resultado de uma pesquisa" (URBIZAGASTEGUI, 2008, p.87), e também sendo que "os eventos científicos mostram-se relevantes para a compreensão dos status e dos rumos que a ciência da informação apresenta” (MOREIRA; MORAES, 2016, p.1).

Neste trabalho, procurou-se indicar e discutir: as quantidades de publicações em todas as edições, por grupo de trabalho (GT), a característica das autorias (incluindo-se a aplicação da Lei de Lotka), posição da autoria, seja nas edições ou por grupo de trabalho, quantidade de autores (principais $-1^{\circ}$ autor e coautores - demais), e principais autores do evento.

Para desenvolver o presente estudo, inicialmente são apresentados, o histórico e aspectos do evento estudado, seguido dos fundamentos metodológicos e os procedimentos adotados para a sua realização, por fim, os principais resultados e considerações finais, seguidas pelas referências.

\section{Encontro Nacional de Pesquisa em Ciência da Informação}

O principal evento da área de Ciência da Informação do País, voltado para a pesquisa, estimula docentes, pesquisadores, estudantes de pós-graduação e profissionais da área, para a reflexão e compartilhamento de produção científica, dirigido à troca de experiência acadêmica e fortalecimento de traços acadêmicos, denomina-se Encontro Nacional de Pesquisa em Ciência da Informação - ENANCIB, que para Noronha et al (2007, p.183) "constituem [...] como um evento que tem contribuído tanto no entrosamento dos membros envolvidos na pósgraduação da área, como na possibilidade de se conhecer o atual estado da arte da pesquisa e sua tendência evolutiva".

No ano de 2019, encontra-se na XX edição, que será realizada em Florianópolis, Santa Catarina, no mês de outubro com o tema "A ciência da informação e a era da ciência de dados", e a Associação Nacional de Pesquisa e Pós-Graduação em Ciência da Informação - ANCIB, em uma das suas frentes, estrutura o evento. 


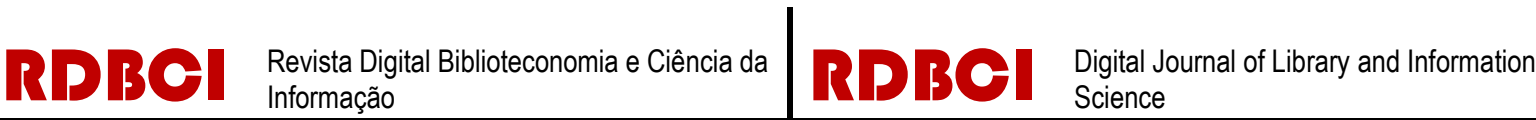

A Ancib, fundada em junho de 1989, é uma sociedade civil, sem fins lucrativos, que tem como finalidade "acompanhar e estimular as atividades de ensino de pós-graduação e de pesquisa em Ciência da Informação no Brasil” (ANCIB, 2019).

O Enancib "tem por finalidade discutir e refletir os temas, perspectivas e tendências da pesquisa em Ciência da Informação, de modo a estimular e promover o avanço da geração de conhecimento na área [...], por meio de amplo diálogo entre pesquisadores que nela atuam" (ENANCIB, 2019), e a primeira edição ocorreu em 1994, no estado de Minas Gerais, representado no quadro 1. As edições, primeira (1994), segunda (1995) e terceira (1997), não apresentaram, nos seus encontros um tema central definido.

Quadro 1 Histórico, localidade e tema do ENANCIB - 1994 a 2018

\begin{tabular}{|c|c|c|c|c|c|c|}
\hline ENANCIB & ANO & PERÍODO & INSTITUIÇÃO & LOCAL & ESTADO & TEMA \\
\hline $\mathrm{XIX}$ & 2018 & Outubro & UEL & Londrina & PR & "O Sujeito Informacional e as Perspectivas Atuais em Ciência da Informação". \\
\hline XVIII & 2017 & Outubro & UNESP & Marília & $\mathrm{SP}$ & "Informação, Sociedade, Complexidade". \\
\hline XVII & 2016 & Novembro & UFBA & Salvador & BA & $\begin{array}{l}\text { "Descobrimentos da Ciência da Informação: desafios da Multi, Inter e } \\
\text { Transdisciplinaridade (MIT)". }\end{array}$ \\
\hline $\mathrm{XVI}$ & 2015 & Outubro & UFPB & João Pessoa & PB & "Informação, Memória e Patrimônio: do documento às redes". \\
\hline $\mathrm{xV}$ & 2014 & Outubro & UFMG & Belo Horizonte & MG & "Além das 'nuvens': expandindo as fronteiras da Ciência da Informação". \\
\hline XIV & 2013 & $\begin{array}{l}\text { Outubroe } \\
\text { novembro }\end{array}$ & UFSC & Florianópolis & SC & $\begin{array}{l}\text { "Informação e interação: ampliando perspectivas para o desenvolvimento } \\
\text { humano". }\end{array}$ \\
\hline $\mathrm{XIII}$ & 2012 & Outubro & Fiocruz & Rio de Janeiro & RJ & "A sociedade em rede para a inovação e o desenvolvimento humano". \\
\hline XII & 2011 & Outubro & UnB & Brasilia & DF & "Políticas de Informação para a Sociedade". \\
\hline $\mathrm{XI}$ & 2010 & Outubro & $\begin{array}{l}\text { IBICT/UFRJ; } \\
\text { Fiocruz; UNIRIO }\end{array}$ & Rio de Janeiro & RJ & "Inovação e inclusão social: questões contemporâneas da informação". \\
\hline $\mathrm{x}$ & 2009 & Outubro & UFPB & João Pessoa & PB & "A responsabilidade social da Ciência da Informação". \\
\hline $\mathrm{IX}$ & 2008 & $\begin{array}{l}\text { Setembro e } \\
\text { Outubro }\end{array}$ & USP & São Paulo & SP & "Diversidade cultural e políticas de informação". \\
\hline VIII & 2007 & Outubro & UFBA & Salvador & BA & $\begin{array}{l}\text { "Promovendo a inserção internacional da pesquisa brasileira em Ciência da } \\
\text { Informação". }\end{array}$ \\
\hline VII & 2006 & Novembro & Unesp & Marília & SP & $\begin{array}{l}\text { "A dimensão epistemológica da Ciência da Informação e suas interfaces } \\
\text { técnicas, políticas e institucionais nos processos de produção, acesso e }\end{array}$ \\
\hline VI & 2005 & Novembro & UFSC & Florianópolis & SC & "A política científica e os desafios da sociedade da informação". \\
\hline $\mathrm{v}$ & 2003 & Novembro & UFMG & Belo Horizonte & MG & "Informação, conhecimento e transdisciplinaridade". \\
\hline IV & 2000 & Novembro & UnB & Brasilia & DF & $\begin{array}{l}\text { "Conhecimento para o Século XXI: a pesquisa na construção da Sociedade da } \\
\text { Informação". }\end{array}$ \\
\hline III & 1997 & Setembro & IBICT/UFRJ & Rio de Janeiro & RJ & \\
\hline II & 1995 & Novembro & PUC-Campinas & Valinhos & $\mathrm{SP}$ & \\
\hline I & 1994 & Abril & UFMG & Belo Horizonte & MG & \\
\hline
\end{tabular}

Fonte: Elaborado pelos autores (2019)

Deste a VI edição (2005) os encontros ocorrem anualmente, em diversos estados no território Brasileiro, que é dividido em cinco regiões (Norte, Nordeste, Centro-Oeste, Sudeste e Sul). Existe o predomínio da região Sudeste com 52,6\% (compreende aos estados de São Paulo, Rio de Janeiro e Minas Gerais - totalizando dez edições) na localidade da realização do evento, seguido da região Nordeste (João Pessoa e Salvador, com quatro edições), região Sul (Paraná e Santa Catarina, com três edições) e região Centro Oeste (Distrito Federal, com duas realizações). 


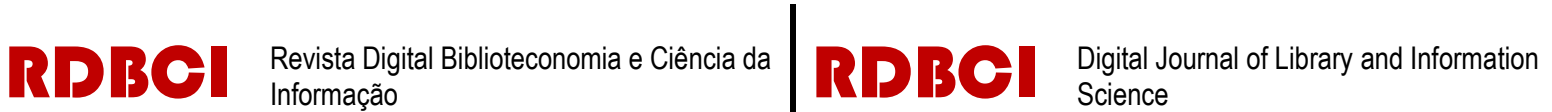

\section{Método}

A pesquisa é de abordagem quantitativa, classificada como exploratória e descritiva. Como método de pesquisa adotou-se a bibliográfica, tendo como corpus os trabalhos publicados no Enancib no período compreendido desde a primeira edição (I - 1994), até a última edição (XIX - 2018). Todas as edições disponibilizam via acesso eletrônico, na página denominada do respectivo evento ou na página da Ancib, o link de acesso das edições (http://enancib.ibict.br/index.php/enancib/index/schedConfs/archive).

A coleta dos dados ocorreu manualmente e foram inseridos em uma planilha eletrônica, com a utilização do software MS-Excel, que compreende os seguintes campos: edição ( $n^{\circ}$ que representa a edição I ao XIX), ano (ano do evento), grupo de trabalho (grupo de trabalho ou sessão temática que pertence o trabalho), comunicação (classificado em pôster ou trabalho completo) e autores (nome dos pesquisadores que desenvolveram a pesquisa) (quadro 2).

Quadro 2. Campo coletados dos itens do ENANCIB - 1994 a 2018

\begin{tabular}{|c|c|c|c|c|c|}
\hline Edição & Ano & Grupo de Trabalho & Comunicação & Autor & Coautor 1 até o 18 \\
\hline $\begin{array}{c}\text { no. da edição } \\
\text { que representa } \\
\text { (I a XIX) }\end{array}$ & $\begin{array}{c}\text { Ano do } \\
\text { evento }\end{array}$ & $\begin{array}{c}\text { Grupo de Trabalho (GT) } \\
\text { ou sessão temática que } \\
\text { pertence o trabalho }\end{array}$ & $\begin{array}{c}\text { Classificado em } \\
\text { pôster ou trabalho } \\
\text { completo }\end{array}$ & $\begin{array}{c}\text { Responsável pelo } \\
\text { desenvolvimento da } \\
\text { pesquisa }\end{array}$ \\
\hline \multicolumn{3}{|c|}{ Quantidade de itens } & Nome dos autores \\
\hline
\end{tabular}

Fonte: Elaborado pelos autores (2019)

Os campos edição, ano, grupo de trabalho e comunicação foram utilizados para a quantificação dos itens, quanto a evolução da produção científica (por edição, por grupo de trabalho, quantitativo de autores em cada grupo) e o campo autores para a definição dos autores mais produtivos (seja pela edição, por grupo de trabalho ou no evento como um todo), pela aplicação da Lei de Lotka (BEUREN; SILVA, 2014; GUEDES, 2012; URBIZAGASTEGUI, 2008). No campo dos autores, houve a necessidade de investigar o nome completo dos autores para padronização, em virtude de nem todos os itens apresentarem o nome completo. A investigação ocorre em virtude de não padronização quanto a abreviação dos nomes entre as 19 edições como (Carlos H. Marcondes - Carlos Henrique Marcondes; Carmen Irene C. de Oliveira - Carmen Irene Correia de Oliveira, entre outros). Assim, foram consultados na base coletada dos autores, se o mesmo do sobrenome abreviado já obteve publicação no evento, caso sim padronizado e ao contrário a consulta no lattes do pesquisador.

\section{Resultados: apresentação e discussão}

A análise compreende o Encontro Nacional de Pesquisa em Ciência da Informação ENANCIB, dos anos de 1994 a 2018, da primeira a décima nona edição. A análise compreende 4.282 itens, sendo 3.843 trabalhos completos e 439 na modalidade de pôster. Nesses dados, a 


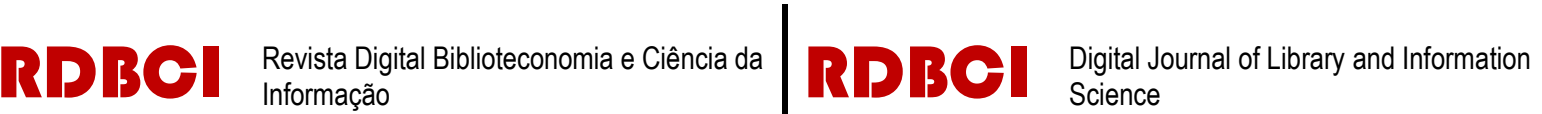

média de publicação foi 225 itens, com um desvio padrão de 119, o desvio padrão elevado se deve ao fato de existirem poucas publicações nas primeiras edições. No entanto, verifica-se uma tendência de crescimento, em trabalho completo e pôster representado pela linha tracejada em vermelho (quadro1).

Gráfico 1. Evolução da produção científica - I a XIX Edição do Encontro Nacional de Pesquisa em Ciência da Informação

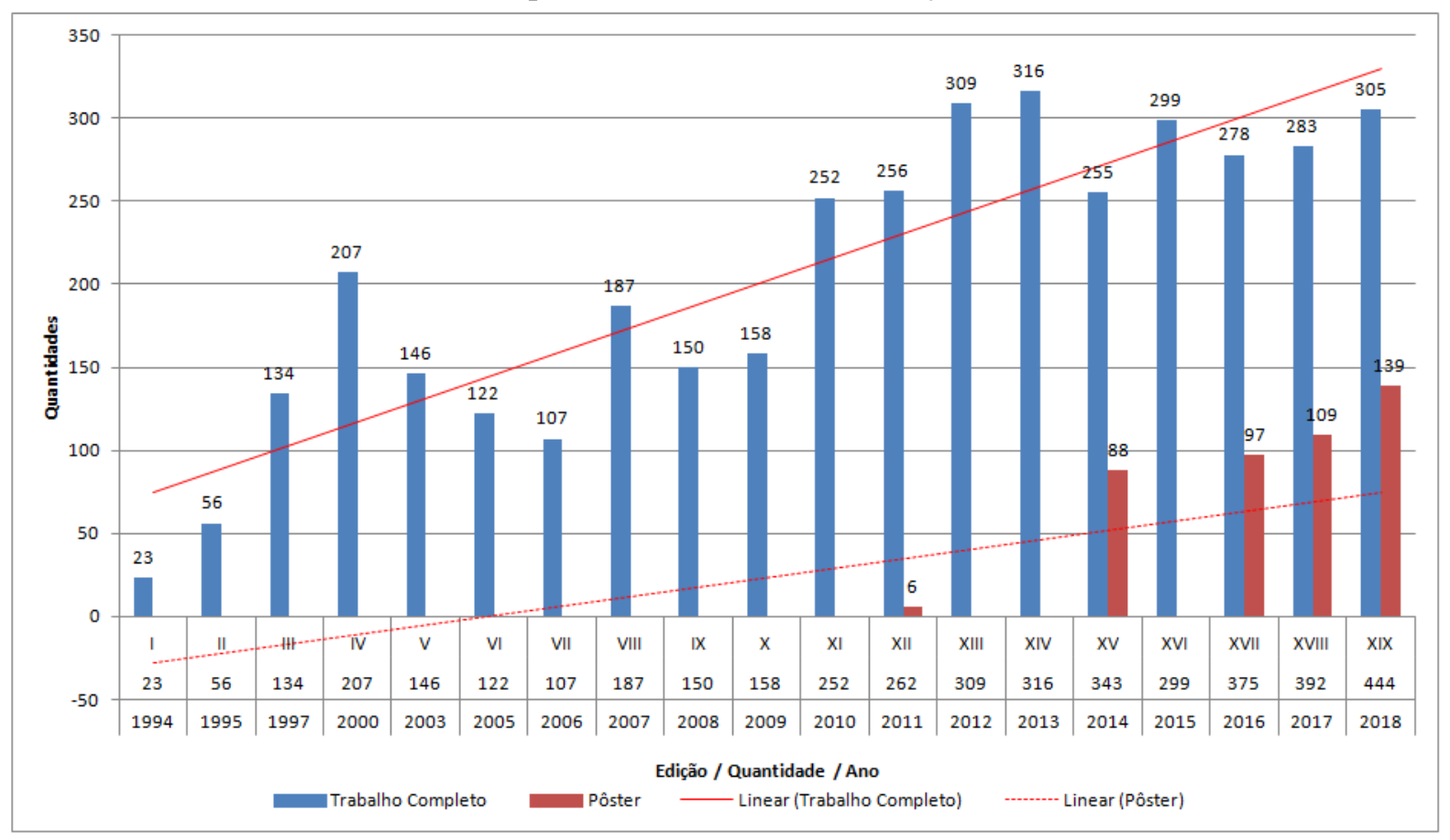

Fonte: Elaborado pelos autores (2019).

Neste contexto, as publicações iniciaram com 23 ocorrências em 1994, apresentando crescimento em praticamente todos os anos com exceção (2003, 2005, 2006, 2008 e 2015), que ocorreu queda em relação ao seu ano anterior. A queda ocasionada deve-se a alguns grupos de trabalho, terem ocasionado uma diminuição de publicações em relação ao ano anterior, com maior expressão, como em 2005 o GT 4 - Gestão da informação e do conhecimento; 2006 GT 3 - Medição, circulação e apropriação da informação; 2008 GT 2 - Organização e representação do conhecimento e GT 7 - Produção e comunicação da informação em ciência, tecnologia \& inovação; e 2015 GT 7 - Produção e comunicação da informação em ciência, tecnologia \& inovação.

O pico de publicações aconteceu em 2018 com 444 itens (tanto como trabalho completo quanto pôster), com um crescimento de $13,27 \%$ em relação ao ano anterior. Tomando como base as XIX edições e o total de publicações no decorrer dos 24 anos do Enancib, a média de publicação é de praticamente 225 itens, sendo ultrapassado esse valor depois da XI edição (2010), em todas as edições após esse período. 


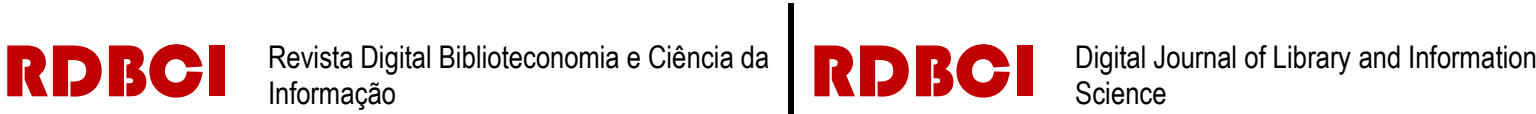

Nas edições (I, II, III) os trabalhos estão separados em sessões temáticas e na IV edição, os trabalhos estão listado em ordem alfabética, em virtude de não ocorrer uma uniformização para os grupos de trabalhos publicados, os respectivos itens (23, 56, 134 e 207), serão desprezados para análises posteriores, também serão desprezados sete itens da $\mathrm{V}$ edição (em virtude da classificação submissões gerais) e quatro itens da XVII (em virtude de apresentar a classificação como conferência dos pesquisadores convidados). Assim, o novo corpus de análise será constituído de 3851 itens (trabalho completo e pôster).

Assim, as edições de V a XIX, de 2003 a 2018, foram separadas pelos grupos de trabalhos, que conforme Rabello (2013, p.157) "pode abranger dois tipos: a) grupo de pessoas que trabalham num mesmo projeto ou b) grupo de pessoas que compartilham informações num mesmo interesse funcional e/ou disciplinar".

Os grupos de trabalhos estão denominados de GT1 até GT11, é "resultado da discussão pelo fórum dos coordenadores de grupos de trabalho, ocorrida durante o VI Enancib, [...] denominado critérios para criação, funcionamento e avaliação de grupos de trabalho na Ancib" (ANCIB,2019), com as denominações (GT 1 - Estudos históricos e epistemológicos da ciência da informação; GT 2 - Organização e representação do conhecimento; GT 3 - Medição, circulação e apropriação da informação; GT 4 - Gestão da informação e do conhecimento; GT 5 - Política e economia da informação; GT 6 - Informação, educação e trabalho; GT 7 Produção e comunicação da informação em ciência, tecnologia \& inovação; GT 8 - Informação e tecnologia; GT 9 - Museu, patrimônio e informação; GT 10 - Informação e memória, e GT 11 - Informação e Saúde), dependendo da edição, existe uma quantificação do número de GT e algumas especificidades da edição, conforme quadro 3:

Quadro 3. Quantificação da produção científica por grupo de trabalho - V a XIX Edição do Encontro Nacional de Pesquisa em Ciência da Informação

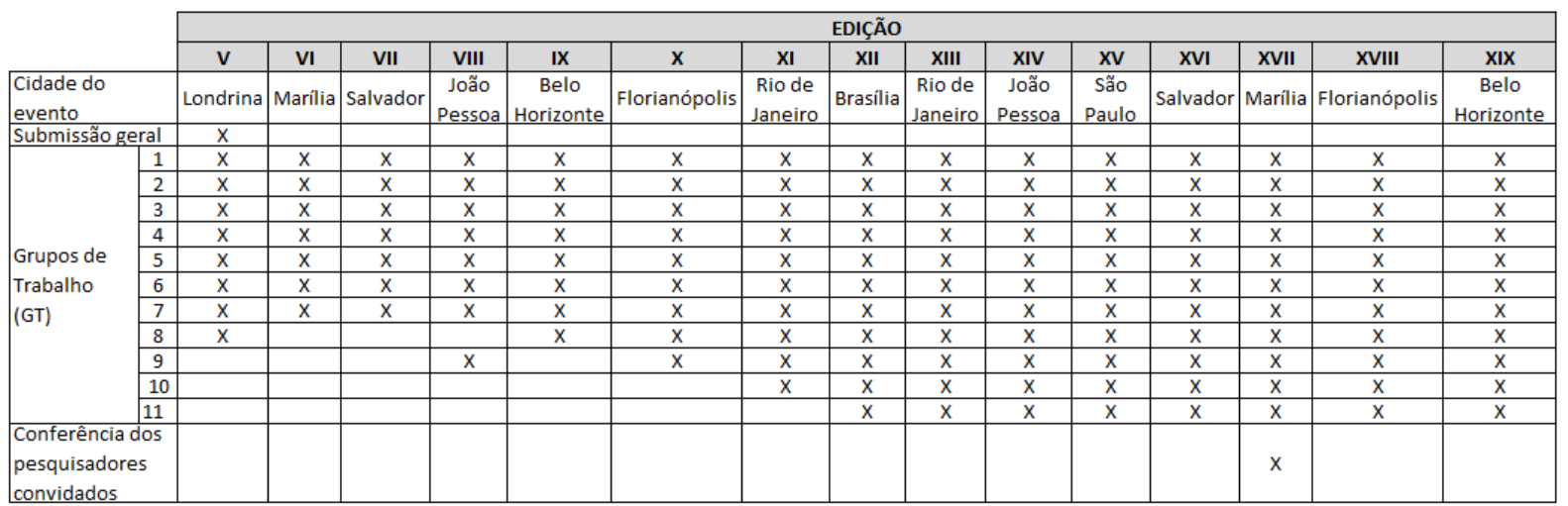

Fonte: Elaborado pelos autores (2019).

Após a classificação e união das edições (V a XIV), conforme quadro 4, pode-se observar o quantitativo de itens por grupo de trabalho, por edição, e se o respectivo grupo 


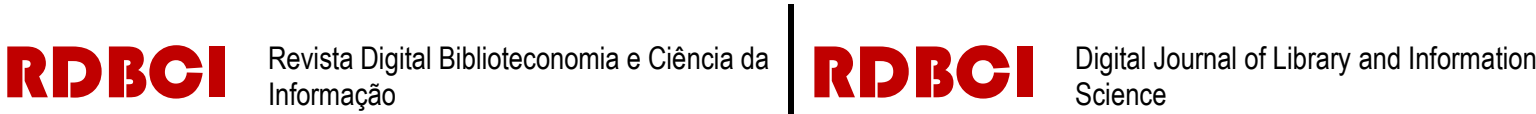

obteve um crescimento (representado pela cor verde), igualdade (representado pela cor amarela) e diminuição (representado pela cor vermelha) em relação a sua edição anterior.

Quadro 4. Evolução da produção científica por grupo de trabalho - V a XIX Edição do Encontro Nacional de Pesquisa em Ciência da Informação

\begin{tabular}{|c|c|c|c|c|c|c|c|c|c|c|c|c|c|c|c|c|c|c|c|c|c|c|c|c|c|c|c|c|c|c|}
\hline Ano & 2003 & 2005 & \multirow{2}{*}{ C } & \multirow{2}{*}{\begin{tabular}{|c|}
2006 \\
VII \\
\end{tabular}} & \multirow{2}{*}{ C } & \multirow{2}{*}{$\begin{array}{r}2007 \\
\text { VIIII }\end{array}$} & \multirow{2}{*}{ C } & \multirow{2}{*}{\begin{tabular}{|c|}
2008 \\
$I X$ \\
\end{tabular}} & \multirow{2}{*}{ C } & \multirow{2}{*}{\begin{tabular}{|c|}
2009 \\
$x$ \\
\end{tabular}} & \multirow{2}{*}{ c } & \multirow{2}{*}{\begin{tabular}{|c|}
2010 \\
$X I$ \\
\end{tabular}} & \multirow{2}{*}{ C } & \multirow{2}{*}{\begin{tabular}{|c|}
2011 \\
XII \\
\end{tabular}} & \multirow{2}{*}{ C } & \multirow{2}{*}{\begin{tabular}{|c|}
2012 \\
XIII \\
\end{tabular}} & \multirow{2}{*}{ c } & \multirow{2}{*}{\begin{tabular}{|c|}
2013 \\
XIV \\
\end{tabular}} & \multirow{2}{*}{ C } & \multirow{2}{*}{\begin{tabular}{|c|}
2014 \\
$X V$ \\
\end{tabular}} & \multirow{2}{*}{ c } & \multirow{2}{*}{\begin{tabular}{|c|}
2015 \\
$X V I$ \\
\end{tabular}} & \multirow[b]{2}{*}{ C } & \multirow{2}{*}{\begin{tabular}{|c|}
2016 \\
$X V I I$ \\
\end{tabular}} & \multirow[t]{2}{*}{$c$} & \multirow{2}{*}{\begin{tabular}{|l|}
2017 \\
$X V I I I$ \\
\end{tabular}} & & \multirow{2}{*}{\begin{tabular}{|c|}
2018 \\
$X I X$ \\
\end{tabular}} & & Total \\
\hline Edição & V & VI & & & & & & & & & & & & & & & & & & & & & & & & & & & $c$ & Iota \\
\hline GT1 & 17 & 16 & 0 & 14 & 0 & 20 & 0 & 21 & 0 & 17 & 0 & 20 & 0 & 23 & 0 & 28 & 0 & 25 & 0 & 20 & 0 & 18 & 0 & 29 & 0 & 27 & 0 & 29 & 0 & 324 \\
\hline GT2 & 17 & 25 & 0 & 23 & 0 & 46 & 0 & 23 & 0 & 29 & 0 & 29 & 0 & 35 & 0 & 28 & 0 & 40 & 0 & 54 & 0 & 36 & 0 & 61 & 0 & 65 & 0 & 49 & 0 & 560 \\
\hline GT3 & 17 & 31 & 0 & 21 & 0 & 27 & 0 & 20 & 0 & 20 & 0 & 19 & 0 & 24 & 0 & 34 & 0 & 32 & 0 & 24 & 0 & 25 & 0 & 29 & 0 & 37 & 0 & 53 & 0 & 413 \\
\hline GT4 & 24 & 12 & 0 & 19 & 0 & 23 & 0 & 16 & 8 & 10 & 0 & 42 & 0 & 24 & 0 & 24 & 0 & 33 & 0 & 37 & 0 & 40 & 0 & 42 & 0 & 46 & 0 & 62 & 0 & 454 \\
\hline GT5 & 14 & 13 & 0 & 11 & 0 & 17 & 0 & 23 & 0 & 23 & 0 & 21 & 0 & 26 & 0 & 31 & 0 & 25 & 0 & 32 & 0 & 24 & 0 & 27 & 0 & 32 & 0 & 45 & 0 & 364 \\
\hline GT6 & 20 & 10 & 0 & 7 & 0 & 8 & 0 & 17 & 0 & 13 & 0 & 21 & 0 & 16 & 0 & 21 & 0 & 18 & 0 & 25 & 0 & 16 & 0 & 22 & 0 & 22 & 0 & 25 & 0 & 261 \\
\hline GT7 & 15 & 15 & 0 & 12 & 0 & 29 & 0 & 14 & 0 & 11 & 0 & 25 & 0 & 28 & 0 & 30 & 0 & 37 & 0 & 41 & 0 & 29 & 0 & 48 & 0 & 57 & 0 & 45 & 0 & 436 \\
\hline GT8 & 15 & & 0 & & & & & 16 & 0 & 20 & 0 & 27 & 0 & 22 & 0 & 30 & 0 & 40 & 0 & 37 & 0 & 32 & 0 & 31 & 0 & 44 & 0 & 48 & 0 & 362 \\
\hline GT9 & & & & & & 17 & 0 & & & 15 & 0 & 12 & 0 & 17 & 0 & 22 & 0 & 19 & 0 & 23 & 0 & 22 & 0 & 20 & 0 & 19 & 0 & 31 & 0 & 217 \\
\hline GT10 & & & & & & & & & & & & 36 & 0 & 34 & 0 & 38 & 0 & 27 & 0 & 35 & 0 & 37 & 0 & 42 & 0 & 27 & 0 & 45 & 0 & 321 \\
\hline GT11 & & & & & & & & & & & & & & 13 & 0 & 23 & 0 & 20 & 0 & 15 & 0 & 20 & 0 & 20 & 0 & 16 & 0 & 12 & 0 & 139 \\
\hline Total & 139 & \begin{tabular}{|l|l}
123 \\
\end{tabular} & & 108 & & 187 & & 151 & & 159 & & 253 & & 262 & & 309 & & 316 & & 343 & & 299 & & 371 & & 392 & & 444 & & 3851 \\
\hline & & & & & & & & & ii & & & & of & o an & din & & est & Ogrc & & $\mathrm{rab}$ & & & & & & & & & & \\
\hline Legend & & 0 & Aum & nento & $\mathrm{em} \mathrm{re}$ & lação & ao a & no ant & erior & & & & & 0 & Igual & dade e & $\mathrm{m} \mathrm{re}$ & lação a & ao an & no ante & rior & & & 0 & Men & or em r & relaç & ão ao a & ano a & nterior \\
\hline
\end{tabular}

Fonte: Elaborado pelos autores (2019).

Verifica-se, que em todos os grupos de trabalho existem diminuições e aumentos em relação ao seu mesmo grupo, em edição anterior, com destaque para o grupo 4 (Gestão da informação e do conhecimento), que nas últimas seis edições veem apresentando crescimento (representado pela cor verde). Pode-se obervar-que o grupo de trabalho 10 (Informação e memória) sendo apresentado desde 2010, iguala praticamente ao grupo 1 (Estudos históricos e epistemológicos da ciência da informação) que veem sendo disponibilizado desde 2003, demonstrando que os pesquisadores estão tendo interesse no estudo "sobre a relação entre os campos de conhecimento da Ciência da Informação e da Memória Social. Pesquisas transdisciplinares [...] Memória coletiva [...] Representações sociais e conhecimento [...] Articulação entre arte, cultura, tecnologia, informação em memória [...] Preservação e virtualização da memória social" (ENANCIB, 2019). Destaque também, para o grupo de trabalho 3 (Mediação, Circulação e Apropriação da Informação) representado pelo "estudo dos processos [...] em diferentes contextos e tempos históricos [...] bem com contribuições teóricometodólogicas diversificadas em sua constituição" (ENANCIB, 2019), compõem produções de métricas da informação (infometria, bibliometria, webmetria, altimetria, etc) representa uma média de 27 itens e um desvio padrão de nove itens, com um crescimento nas últimas edições (desde a XVI, 2015).

Em relação ao número de autores por item e por grupo de trabalho, os dados evidenciam uma variação entre um e 18, autores para cada item, com exceção $(10,12,13,14,15,16$ e 17), que em nenhum item possui esse quantitativo de autores. Para o estudo, considera-se como "autor principal" aquele que está na primeira posição do item, e como coautores os que estão da segunda (2a posição em diante. Conforme Youtie; Borzeman (2014) e Hilário; Grácio; Wolfram (2017) o autor de maior contribuição científica e intelectual para a pesquisa aparece como o primeiro autor. 


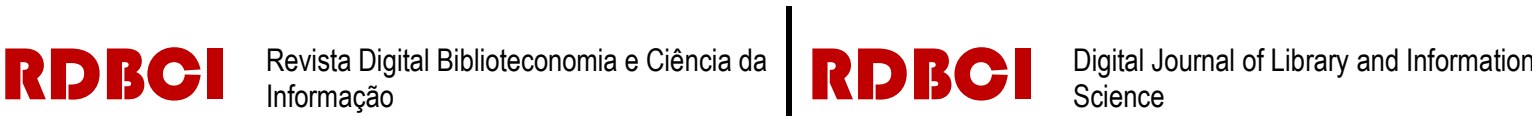

No quadro 5, apresenta-se o quantitativo de trabalho produzidos em relação as autorias, iniciando com apenas única autoria, em colaboração com dois, até dezoito, separado por grupo de trabalho.

Quadro 5. Frequência e número de itens publicados dos autores por grupo de trabalho - V a XIX Edição do Encontro Nacional de Pesquisa em Ciência da Informação

\begin{tabular}{|c|c|c|c|c|c|c|c|c|c|c|c|c|c|c|c|}
\hline \multirow[b]{2}{*}{ Grupos de Trabalhos } & \multicolumn{12}{|c|}{ Quantidade de autores por trabalho } & \multirow[b]{2}{*}{ Total } & \multirow[b]{2}{*}{$\%$} & \multirow[b]{2}{*}{$\%$ acum } \\
\hline & 1 & 2 & 3 & 4 & 5 & 6 & 7 & 8 & 9 & 11 & 14 & 18 & & & \\
\hline $\begin{array}{l}\text { GT 1: Estudos Históricos e Epistemológicos } \\
\text { da Ciência da Informação }\end{array}$ & 150 & 138 & 22 & 8 & 3 & 2 & & 1 & & & & & 324 & 8,41 & 8,41 \\
\hline $\begin{array}{l}\text { GT 2: Organização do Conhecimento e } \\
\text { Representação da Informação }\end{array}$ & 106 & 354 & 71 & 15 & 5 & 7 & 1 & & & & 1 & & 560 & 14,54 & 22,96 \\
\hline $\begin{array}{l}\text { GT 3: Mediação, Circulação e Apropriação } \\
\text { da Informação }\end{array}$ & 107 & 240 & 42 & 15 & 2 & 4 & 1 & & 2 & & & & 413 & 10,72 & 33,68 \\
\hline $\begin{array}{l}\text { GT } 4 \text { : Gestão da Informação e do } \\
\text { Conhecimento nas Organizações }\end{array}$ & 67 & 276 & 70 & 25 & 11 & 4 & 1 & & & & & & 454 & 11,79 & 45,47 \\
\hline GT 5 : Política e Economia da Informação & 89 & 212 & 48 & 12 & 2 & & 1 & & & & & & 364 & 9,45 & 54,92 \\
\hline GT 6 : Informação, Educação e Trabalho & 56 & 147 & 33 & 15 & 8 & & & 2 & & & & & 261 & 6,78 & 61,70 \\
\hline $\begin{array}{l}\text { GI I:Produçao comuntcaçao da } \\
\text { Informação em Ciência, Tecnologia \& }\end{array}$ & 62 & 239 & 89 & 30 & 14 & 1 & & 1 & & & & & 436 & 11,32 & 73,02 \\
\hline 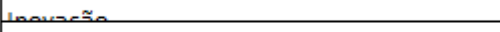 & & & & & & & & & & & & & & & \\
\hline GT 8: Informação e Tecnologia & 45 & 187 & 78 & 25 & 15 & 7 & 3 & 1 & & 1 & & & 362 & 9,40 & 82,42 \\
\hline GT 9 : Museologia, Patrimônio e Informação & 78 & 106 & 27 & 4 & & 1 & 1 & & & & & & 217 & 5,63 & 88,06 \\
\hline GT 10: Informação e Memória & 92 & 152 & 64 & 11 & 2 & & & & & & & & 321 & 8,34 & 96,39 \\
\hline GT 11: Informação e Saúde & 7 & 78 & 30 & 14 & 8 & 1 & & & & & & 1 & 139 & 3,61 & 100,00 \\
\hline Total & 859 & 2.129 & 574 & 174 & 70 & 27 & 8 & 5 & 2 & 1 & 1 & 1 & 3.851 & 100,00 & \\
\hline$\%$ & 22,31 & 55,28 & 14,91 & 4,52 & 1,82 & 0,70 & 0,21 & 0,13 & 0,05 & 0,03 & 0,03 & 0,03 & 100,00 & & \\
\hline
\end{tabular}

Fonte: Elaborado pelos autores (2019).

O grupo de trabalho 1 (estudos históricos e epistemológicos da ciência da informação), apresenta predomínio de publicação com autoria única, mas tendo a publicação de até oito autores, tendo a representatividade de 324 autores que já publicaram nesse grupo, que corresponde $8,41 \%$ do total, das obras analisados nos 11 GT. Os grupos de trabalhos de 2 até 11, existe predomínio de publicação com dois autores, o que representa mais da metade dos itens foram produzidos pelo autor principal mais um coautor $(55,28 \%)$. No GT 2, existe superioridade em relação aos demais GT, quanto a quantidade de publicações (14,54\%), variando de apenas um autor (106) até 14 autores em um único item. O GT 11 (Informação e saúde) foi o que apresentou o maior quantitativo de autor em um único (18) item.

Para conhecer os autores mais produtivos nos eventos por edição e por grupo de trabalho, ordenou-se tais pesquisadores a partir do número de trabalhos publicados. Dos "três tipos de contagem da literatura produzida: contagem direta, contagem completa e contagem fracionada" (URBIZAGASTEGUI, 2008, p.87), foi utilizado a forma contagem completa, que

v.17

$1-21$

e019038




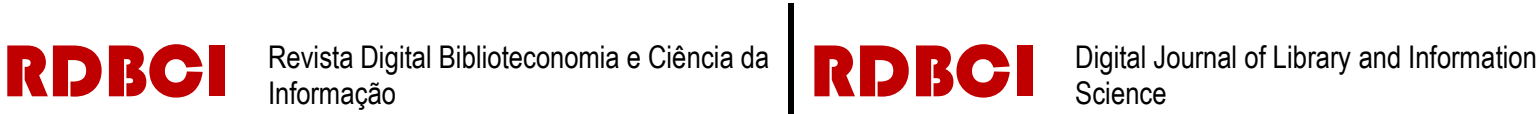

"credita a produtividade a todos os colaboradores, independente de se eles participaram da produção do trabalho como principais ou colaboradores" (URBIZAGASTEGUI, 2008, p.95).

Em relação a quantidade de autores, da quinta (V) até a décima nona (XIX) edição, foram 8204 autores, independente de qual a posição ocupa em cada item, quanto a segundo, terceiro e assim por diante (quadro 6).

Quadro 6. Quantidade de autores por grupo de trabalho (GT 1 - GT 11) - V a XIX Edição do Encontro Nacional de Pesquisa em Ciência da Informação

\begin{tabular}{|c|c|c|c|c|c|c|c|c|c|c|c|c|c|c|c|c|c|c|c|}
\hline Grupo de Trabalho & v & VI & VII & VIII & IX & $x$ & $\mathbf{X I}$ & XII & XIII & XIV & XV & $\mathrm{XVI}$ & XVII & XVIII & $\mathbf{X I X}$ & Total & Média & Máx. & Min. \\
\hline GT 1 & 33 & 21 & 22 & 32 & 36 & 30 & 32 & 37 & 46 & 39 & 32 & 28 & 56 & 60 & 55 & 559 & 37 & 60 & 21 \\
\hline GT 2 & 40 & 42 & 46 & 90 & 55 & 53 & 61 & 71 & 53 & 89 & 115 & 72 & 127 & 151 & 110 & 1175 & 78 & 151 & 40 \\
\hline GT 3 & 26 & 63 & 40 & 50 & 52 & 37 & 42 & 46 & 69 & 65 & 46 & 51 & 60 & 73 & 112 & 832 & 55 & 112 & 26 \\
\hline GT 4 & 33 & 29 & 36 & 49 & 36 & 20 & 83 & 43 & 48 & 76 & 88 & 96 & 99 & 114 & 165 & 1015 & 68 & 165 & 20 \\
\hline GT 5 & 25 & 24 & 19 & 33 & 45 & 47 & 45 & 46 & 59 & 56 & 64 & 44 & 54 & 66 & 95 & 722 & 48 & 95 & 19 \\
\hline \begin{tabular}{|l|} 
GT 6 \\
\end{tabular} & 35 & 24 & 20 & 17 & 33 & 33 & 39 & 37 & 47 & 36 & 51 & 33 & 48 & 56 & 56 & 565 & 38 & 56 & 17 \\
\hline \begin{tabular}{|l|} 
GT 7 \\
\end{tabular} & 30 & 31 & 21 & 61 & 36 & 22 & 57 & 67 & 71 & 88 & 94 & 65 & 105 & 139 & 124 & 1011 & 67 & 139 & 21 \\
\hline \begin{tabular}{|l|} 
GT 8 \\
\end{tabular} & 31 & & & & 35 & 50 & 73 & 54 & 75 & 101 & 84 & 70 & 92 & 117 & 128 & 910 & 76 & 128 & 31 \\
\hline \begin{tabular}{|l|} 
GT 9 \\
\end{tabular} & & & & 31 & & 26 & 20 & 28 & 40 & 36 & 42 & 39 & 44 & 30 & 64 & 400 & 36 & 64 & 20 \\
\hline GT 10 & & & & & & & 59 & 61 & 73 & 52 & 77 & 72 & 85 & 59 & 104 & 642 & 71 & 104 & 52 \\
\hline GT 11 & & & & & & & & 36 & 77 & 54 & 44 & 49 & 45 & 40 & 28 & 373 & 47 & 77 & 28 \\
\hline Total & 253 & 234 & 204 & 363 & 328 & 318 & 511 & 526 & 658 & 692 & 737 & 619 & 815 & 905 & 1041 & 8204 & & & \\
\hline \begin{tabular}{|l|} 
Média \\
\end{tabular} & 32 & 33 & 29 & 45 & 41 & 35 & 51 & 48 & 60 & 63 & 67 & 56 & 74 & 82 & 95 & & & & \\
\hline \begin{tabular}{|l|} 
Máximo \\
\end{tabular} & 40 & 63 & 46 & 90 & 55 & 53 & 83 & 71 & 77 & 101 & 115 & 96 & 127 & 151 & 165 & & & & \\
\hline Mínimo & 25 & 21 & 19 & 17 & 33 & 20 & 20 & 28 & 40 & 36 & 32 & 28 & 44 & 30 & 28 & & & & \\
\hline
\end{tabular}

Fonte: Elaborado pelos autores (2019).

Observa-se que a edição XIX, realizada em 2018, apresenta o maior quantitativo de autores (1041), tendo a média de 95 autores, com o GT 11 apresentando a menor quantidade (28) e o GT 4 maior (165). Nota-se também um crescimento em cada edição do número de autores, tendo o predomínio do GT 2 (1175) autores, seguido do GT4 (1015) e GT 7 (1011). Em nenhum grupo de trabalho obteve valor mínimo inferior a 21 pesquisadores, independente da edição, demonstrando o trabalho coletivo que "aprender junto e de fazer junto, da aprendizagem compartilhada, [...] com princípios norteadores e ancorada em conhecimento científico sólido" (ROSSIT; et al, 2018, p.1512).

Tendo como base, as edições V até XIX, foram 8204 pesquisadores, sendo que 38,20\% (3134) são autores diferentes, com destaque para os autores com mais de 30 publicações: Isa Maria Freire (38) publicações, Silvana Aparecida Borsette Gregorio Vidotti (36), Maria Aparecida Moura (34), Plácida Leopoldina Ventura Amorim da Costa Santos (33), Marta Lígia Pomim Valentim (33), Emeide Nobrega Duarte (32), Maria Luiza de Almeida Campos (32), Leilah Santiago Bufrem (32) e Georgete Medleg Rodrigues (30) - quadro 7. 
Quadro 7. Nome e quantidade de autores que mais apresenta publicação - V a XIX Edição do Encontro Nacional de Pesquisa em Ciência da Informação

\begin{tabular}{|c|c|c|c|c|c|}
\hline Pesquisadores (nome) & Publicações & Quant. & Pesquisadores & Publicações & Quant. \\
\hline Isa Maria Freire & 38 & 1 & 5 & 22 & 5 \\
\hline Silvana Aparecida Borsette Gregório Vidotti & 36 & 1 & 3 & 21 & 3 \\
\hline Maria Aparecida Moura & 34 & 1 & 5 & 20 & 5 \\
\hline Marta Lígia Pomim Valentim & 33 & 1 & 5 & 19 & 5 \\
\hline Plácida Leopoldina Ventura Amorim da Costa Santos & 33 & 1 & 14 & 18 & 14 \\
\hline Emeide Nobrega Duarte & 32 & 1 & 11 & 17 & 11 \\
\hline Leilah Santiago Bufrem & 32 & 1 & 8 & 16 & 8 \\
\hline Maria Luiza de Almeida Campos & 32 & 1 & 8 & 15 & 8 \\
\hline Georgete Medleg Rodrigues & 30 & 1 & 6 & 14 & 6 \\
\hline Ely Francina Tannuri de Oliveira & 29 & 1 & 16 & 13 & 16 \\
\hline Beatriz Valadares Cendon & 29 & 1 & 20 & 12 & 20 \\
\hline Rosali Fernandez de Souza & 29 & 1 & 22 & 11 & 22 \\
\hline Ricardo Rodrigues Barbosa & 28 & 1 & 17 & 10 & 17 \\
\hline Renato Rocha Souza & 28 & 1 & 21 & 9 & 21 \\
\hline Marta Macedo Kerr Pinheiro & 27 & 1 & 38 & 8 & 38 \\
\hline Gustavo Silva Saldanha & 27 & 1 & 39 & 7 & 39 \\
\hline Lena Vânia Ribeiro Pinheiro & 27 & 1 & 53 & 6 & 53 \\
\hline Gercina Angela Borém de Oliveira Lima & 27 & 1 & 62 & 5 & 62 \\
\hline Evelyn Goyannes Dill Orrico & 25 & 1 & 104 & 4 & 104 \\
\hline Izabel França de Lima & 25 & 1 & 235 & 3 & 235 \\
\hline $\begin{array}{l}5 \text { pesquisadores (Bernardina Juvenal Freire de } \\
\text { Oliveira; Marcus Granato; Nanci Oddone; Regina } \\
\text { Maria Marteleto; Sonia Elisa Caregnato) }\end{array}$ & 24 & 5 & 486 & 2 & 486 \\
\hline $\begin{array}{l}3 \text { pesquisadores (Giulia Crippa; Guilherme Ataide Dias; } \\
\text { Mauricio Barcelos de Almeida) }\end{array}$ & 23 & 3 & 1928 & 1 & 1928 \\
\hline \multicolumn{2}{|l|}{ Total de pesquisadores } & 28 & \multicolumn{2}{|c|}{ Total de pesquisadores } & 3106 \\
\hline
\end{tabular}

Fonte: Elaborado pelos autores (2019).

Nota-se a elevada quantidade de autores (1928 - 61,52\%) com apenas uma publicação, sendo que o quantitativo de publicidade por pesquisador varia em até 38 (exceções 26, 31,35 e 37). Os autores com menos de dez publicações (2966), equivale a 95,49\% do total de pesquisadores do V ao XIX edição do Enancib.

Neste contexto, os autores mais produtivos nos 11 grupos de trabalhos estão presentes dos quadros de 8 até 18. Observa-se que a maior produção por grupo de trabalhos, está no GT 2 (Maria Luiza de Almeida Campos - 30) que está entre as pesquisadoras com maior publicação no Enancib. 
IPAO $\begin{aligned} & \text { Revista Digital Biblioteconomia e Ciência da } \\ & \text { Informação }\end{aligned}$

Quadro 8. Autores mais produtivos no GT1 - V

a XIX Edição do Encontro Nacional de Pesquisa em Ciência da Informação

\begin{tabular}{|l|c|}
\hline Pesquisadores & Quant. \\
\hline Edivanio Duarte de Souza & 17 \\
\hline Gustavo Silva Saldanha & 16 \\
\hline Lena Vânia Ribeiro Pinheiro & 13 \\
\hline Georgete Medleg Rodrigues & 13 \\
\hline María Nélida González de Gómez & 11 \\
\hline
\end{tabular}

Fonte: Elaborado pelos autores (2019).

Quadro 10. Autores mais produtivos no GT3 V a XIX Edição do Encontro Nacional de

Pesquisa em Ciência da Informação

\begin{tabular}{|l|c|}
\hline Pesquisadores & Quant. \\
\hline Regina Maria Marteleto & 18 \\
\hline Helen de Castro Silva Casarin & 13 \\
\hline Adriana Bogliolo Sirihal Duarte & 13 \\
\hline Giulia Crippa & 13 \\
\hline Marco Antonio Almeida & 12 \\
\hline
\end{tabular}

Fonte: Elaborado pelos autores (2019).

Quadro 12. Autores mais produtivos no GT5 V a XIX Edição do Encontro Nacional de Pesquisa em Ciência da Informação

\begin{tabular}{|l|c|}
\hline Pesquisadores & Quant. \\
\hline Marta Macedo Kerr Pinheiro & 24 \\
\hline Sarita Albagli & 17 \\
\hline Georgete Medleg Rodrigues & 14 \\
\hline Liz Rejane Issberner & 11 \\
\hline Jose Maria Jardim & 11 \\
\hline
\end{tabular}

Fonte: Elaborado pelos autores (2019).

Quadro 14. Autores mais produtivos no GT7 V a XIX Edição do Encontro Nacional de Pesquisa em Ciência da Informação

\begin{tabular}{|l|c|}
\hline Pesquisadores & Quant. \\
\hline Ely Francina Tannuri de Oliveira & 27 \\
\hline Leilah Santiago Bufrem & 24 \\
\hline Sonia Elisa Caregnato & 19 \\
\hline Maria Cláudia Cabrini Grácio & 18 \\
\hline Nanci Oddone & 17 \\
\hline
\end{tabular}

Fonte: Elaborado pelos autores (2019).
P D $P$ Digital Journal of Library and Information Science

Quadro 9. Autores mais produtivos no GT2 - V a XIX Edição do Encontro Nacional de Pesquisa em Ciência da Informação

\begin{tabular}{|l|c|}
\hline Pesquisadores & Quant. \\
\hline Maria Luiza de Almeida Campos & 30 \\
\hline Gercina Angela Borém de Oliveira Lima & 21 \\
\hline Mariângela Spotti Lopes Fujita & 20 \\
\hline Rosali Fernandez de Souza & 20 \\
\hline Mauricio Barcelos de Almeida & 16 \\
\hline
\end{tabular}

Fonte: Elaborado pelos autores (2019).

Quadro 11. Autores mais produtivos no GT4 V a XIX Edição do Encontro Nacional de Pesquisa em Ciência da Informação

\begin{tabular}{|l|c|}
\hline Pesquisadores & Quant. \\
\hline Emeide Nobrega Duarte & 28 \\
\hline Marta Lígia Pomim Valentim & 26 \\
\hline Ricardo Rodrigues Barbosa & 23 \\
\hline Sueli Angelica do Amaral & 17 \\
\hline Alzira Karla Araújo da Silva & 16 \\
\hline
\end{tabular}

Fonte: Elaborado pelos autores (2019).

Quadro 13. Autores mais produtivos no GT6V a XIX Edição do Encontro Nacional de Pesquisa em Ciência da Informação

\begin{tabular}{|l|c|}
\hline Pesquisadores & Quant. \\
\hline Aida Varela Varela & 12 \\
\hline Helena Maria Tarchi Crivellari & 11 \\
\hline Elizete Vieira Vitorino & 10 \\
\hline Francisco das Chagas de Souza & 10 \\
\hline Isa Maria Freire & 9 \\
\hline
\end{tabular}

Fonte: Elaborado pelos autores (2019).

Quadro 15. Autores mais produtivos no GT8 V a XIX Edição do Encontro Nacional de Pesquisa em Ciência da Informação

\begin{tabular}{|l|c|}
\hline Pesquisadores & Quant. \\
\hline Silvana Aparecida Borsette Gregório Vidotti & 26 \\
\hline Plácida Leopoldina Ventura Amorim da Costa Santos & 22 \\
\hline Marckson Roberto Ferreira de Sousa & 15 \\
\hline Fernando Luiz Vechiato & 15 \\
\hline Guilherme Ataide Dias & 15 \\
\hline
\end{tabular}

Fonte: Elaborado pelos autores (2019). 

RDBCI

Quadro 16. Autores mais produtivos no GT9V a XIX Edição do Encontro Nacional de

Pesquisa em Ciência da Informação

\begin{tabular}{|l|c|}
\hline Pesquisadores & Quant. \\
\hline Marcus Granato & 22 \\
\hline Diana Farjalla Correia Lima & 19 \\
\hline Luisa Maria Gomes de Mattos Rocha & 14 \\
\hline Teresa Cristina Moletta Scheiner & 13 \\
\hline Nilson Alves de Moraes & 10 \\
\hline
\end{tabular}

Fonte: Elaborado pelos autores (2019). RPBOI $\begin{aligned} & \text { Digital Journal of Library and Information } \\ & \text { Science }\end{aligned}$

Quadro 17. Autores mais produtivos no GT10V a XIX Edição do Encontro Nacional de Pesquisa em Ciência da Informação

\begin{tabular}{|l|c|}
\hline Pesquisadores & Quant. \\
\hline Bernardina Juvenal Freire de Oliveira & 22 \\
\hline Izabel França de Lima & 15 \\
\hline Evelyn Goyannes Dill Orrico & 15 \\
\hline Carlos Xavier de Azevedo Netto & 15 \\
\hline Leila Beatriz Ribeiro & 13 \\
\hline
\end{tabular}

Fonte: Elaborado pelos autores (2019).

Quadro 18. Autores mais produtivos no GT11 - V a XIX Edição do Encontro Nacional de Pesquisa em Ciência da Informação

\begin{tabular}{|l|c|}
\hline Pesquisadores & Quant. \\
\hline Cícera Henrique da Silva & 17 \\
\hline Maria Cristina Soares Guimarães & 14 \\
\hline Rosany Bochner & 8 \\
\hline Rosane Abdala Lins de Santana & 6 \\
\hline Rosane Suely Alvares Lunardelli & 5 \\
\hline
\end{tabular}

Fonte: Elaborado pelos autores (2019).

Destaca-se a autora Isa Maria Freire, presente no quadro 5, como a pesquisadora com maior numero de publicação, mas apenas em destaque no GT6 (9 itens), ou seja, tem diversas produções pelos grupos. A autora, Silvana Aparecida Borsette Gregório Vidotti presente com 26 itens no GT8, deixa na segunda posição no Enancib. Quanto aos itens analisados as autoras Maria Aparecida Moura e Marta Lígia Pomim Valentim, não se encontram em destaque em nenhum dos 11 grupo de trabalhos.

Após a análise dos autores mais produtivos, desde a quinta edição até a décima nona, e também por grupo de trabalho, no mesmo período, agora os autores de destaque em cada uma das edições.

Para a edição XIX, que compreende o maior quantitativo de autores (1041) que produziram 444 itens, tendo a autora Leilah Santiago Bufrem o destaque com 7 itens, seguido de Carlos Xavier de Azevedo Neto, Gustavo Silva Saldanha, Izabel França de Lima, Luciana Ferreira da Costa e mais 3 autores com cinco publicações. Com quatro publicações 20 autores, com três publicações 36 autores e assim por diante. Os quadros de 19 a 32 expressam os cinco autores mais produtivos por edição. 


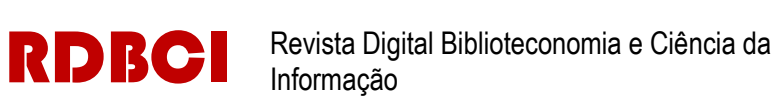

Quadro 19. Autores mais produtivos na V edição (2003) - Encontro Nacional de Pesquisa em

Ciência da Informação

\begin{tabular}{|l|r|}
\hline Nome & Quant. \\
\hline Marta Araujo Tavares Ferreira & 8 \\
\hline Beatriz Valadares Cendon & 2 \\
\hline Carlos Henrique Marcondes & 2 \\
\hline Carmen Irene Correia de Oliveira & 2 \\
\hline Claudio Marcondes de Castro Filho & 2 \\
\hline 14 & 2 \\
\hline 209 & 1 \\
\hline Total Autores / Itens & $\mathbf{2 5 3 / 1 3 9}$ \\
\hline
\end{tabular}

Fonte: Elaborado pelos autores (2019).

Quadro 21. Autores mais produtivos na VII edição (2006) - Encontro Nacional de Pesquisa em Ciência da Informação

\begin{tabular}{|l|r|}
\hline Nome & Quant. \\
\hline Ricardo Rodrigues Barbosa & 4 \\
\hline Jussara Borges de Lima & 3 \\
\hline Marilia Damian Costa & 3 \\
\hline Othon Jambeiro & 3 \\
\hline Antonio Miranda & 2 \\
\hline 19 & 2 \\
\hline 151 & 1 \\
\hline Total Autores / Itens & $\mathbf{2 0 4 / 1 0 8}$ \\
\hline
\end{tabular}

Fonte: Elaborado pelos autores (2019).

Quadro 23. Autores mais produtivos na IX edição (2008) - Encontro Nacional de Pesquisa em Ciência da Informação

\begin{tabular}{|l|r|}
\hline Nome & Quant. \\
\hline Beatriz Valadares Cendon & 4 \\
\hline Plácida Leopoldina Ventura Amorim da Costa Santos & 4 \\
\hline Renato Rocha Souza & 4 \\
\hline Silvana Aparecida Borsette Gregório Vidotti & 4 \\
\hline Clóvis Ricardo Montenegro de Lima & 3 \\
\hline 7 & 3 \\
\hline 22 & 2 \\
\hline 244 & 1 \\
\hline Total Autores / Itens & 328 / 151 \\
\hline
\end{tabular}

Fonte: Elaborado pelos autores (2019).
P D D Digital Journal of Library and Information Science

Quadro 20. Autores mais produtivos na VI edição (2005) - Encontro Nacional de Pesquisa em Ciência da Informação

\begin{tabular}{|l|r|}
\hline Nome & Quant. \\
\hline Jussara Borges de Lima & 4 \\
\hline Mariângela Spotti Lopes Fujita & 4 \\
\hline Nanci Oddone & 4 \\
\hline Sonia Elisa Caregnato & 4 \\
\hline José Augusto Chaves Guimarães & 3 \\
\hline 5 & 3 \\
\hline 17 & 2 \\
\hline 166 & 1 \\
\hline Total Autores / Itens & $\mathbf{2 3 4 / 1 2 3}$ \\
\hline
\end{tabular}

Fonte: Elaborado pelos autores (2019).

Quadro 22. Autores mais produtivos na VIII edição (2007) - Encontro Nacional de Pesquisa em Ciência da Informação

\begin{tabular}{|l|r|}
\hline Nome & Quant. \\
\hline Maria Luiza de Almeida Campos & 5 \\
\hline Gercina Angela Borém de Oliveira Lima & 4 \\
\hline Lillian Alvares & 3 \\
\hline Marcos Luiz Cavalcanti de Miranda & 3 \\
\hline Maria Aparecida Moura & 3 \\
\hline 9 & 3 \\
\hline 37 & 2 \\
\hline 244 & $\mathbf{3 6 3 / 1 8 7}$ \\
\hline Total Autores / Itens & 1 \\
\hline
\end{tabular}

Fonte: Elaborado pelos autores (2019).

Quadro 24. Autores mais produtivos na X edição (2009) - Encontro Nacional de Pesquisa em Ciência da Informação

\begin{tabular}{|l|r|}
\hline Nome & Quant. \\
\hline Isa Maria Freire & 4 \\
\hline Eduardo Ismael Murguia & 3 \\
\hline Guilherme Ataide Dias & 3 \\
\hline Joana Coeli Ribeiro Garcia & 3 \\
\hline João Batista Ernesto Moraes & 3 \\
\hline 7 & 3 \\
\hline 28 & 2 \\
\hline 225 & 1 \\
\hline Total Autores / Itens & $\mathbf{3 1 8 / 1 5 9}$ \\
\hline
\end{tabular}

Fonte: Elaborado pelos autores (2019). 
Quadro 25. Autores mais produtivos na XI edição (2010) - Encontro Nacional de Pesquisa em Ciência da Informação

\begin{tabular}{|l|r|}
\hline Nome & Quant. \\
\hline Isa Maria Freire & 6 \\
\hline Marta Lígia Pomim Valentim & 6 \\
\hline Beatriz Valadares Cendon & 4 \\
\hline Asa Fujino & 3 \\
\hline Dulce Amélia de Brito Neves & 3 \\
\hline 15 & 3 \\
\hline 50 & 2 \\
\hline 344 & 1 \\
\hline Total Autores / Itens & $\mathbf{5 1 1 / 2 5 3}$ \\
\hline
\end{tabular}

Fonte: Elaborado pelos autores (2019).

Quadro 27. Autores mais produtivos na XIII edição (2012) - Encontro Nacional de Pesquisa em Ciência da Informação

\begin{tabular}{|l|r|}
\hline Nome & Quant. \\
\hline Marcello Peixoto Bax & 6 \\
\hline Aida Varela & 4 \\
\hline Bernardina Juvenal Freire de Oliveira & 4 \\
\hline Francisca Arruda Ramalho & 4 \\
\hline Carlos Xavier de Azevedo Netto & 3 \\
\hline 19 & 3 \\
\hline 79 & 2 \\
\hline 422 & 1 \\
\hline Total Autores / Itens & $658 / 309$ \\
\hline
\end{tabular}

Fonte: Elaborado pelos autores (2019).

Quadro 29. Autores mais produtivos na XV edição (2014) - Encontro Nacional de Pesquisa em Ciência da Informação

\begin{tabular}{|l|r|}
\hline Nome & Quant. \\
\hline Mauricio Barcelos de Almeida & 4 \\
\hline Sandra de Albuquerque Siebra & 4 \\
\hline Rosali Fernandez de Souza & 4 \\
\hline Fábio Mascarenhas e Silva & 4 \\
\hline Leilah Santiago Bufrem & 4 \\
\hline 1 & 4 \\
\hline 31 & 3 \\
\hline 86 & 2 \\
\hline 448 & 1 \\
\hline Total Autores / Itens & $\mathbf{7 3 7} / \mathbf{3 4 3}$ \\
\hline
\end{tabular}

Fonte: Elaborado pelos autores (2019).
Quadro 26. Autores mais produtivos na XII edição (2011) - Encontro Nacional de Pesquisa em Ciência da Informação

\begin{tabular}{|l|r|}
\hline Nome & Quant. \\
\hline Marta Macedo Kerr Pinheiro & 5 \\
\hline Májory Karoline Fernandes de Oliveira Miranda & 4 \\
\hline Márcia Regina da Silva & 4 \\
\hline Marcos Galindo de Lima & 4 \\
\hline Ely Francina Tannuri de Oliveira & 3 \\
\hline 7 & 3 \\
\hline 60 & 2 \\
\hline 365 & 1 \\
\hline Total Autores / Itens & $\mathbf{5 2 6 / 2 6 2}$ \\
\hline
\end{tabular}

Fonte: Elaborado pelos autores (2019).

Quadro 28. Autores mais produtivos na XIV edição (2013) - Encontro Nacional de Pesquisa em Ciência da Informação

\begin{tabular}{|l|r|}
\hline Nome & Quant. \\
\hline Marcello Peixoto Bax & 4 \\
\hline Nanci Oddone & 4 \\
\hline Ricardo César Gonçalves Sant'Ana & 4 \\
\hline Sandra de Albuquerque Siebra & 4 \\
\hline Adriana Bogliolo Sirihal Duarte & 3 \\
\hline 32 & 3 \\
\hline 83 & 2 \\
\hline 411 & 1 \\
\hline Total Autores / Itens & $692 / 316$ \\
\hline
\end{tabular}

Fonte: Elaborado pelos autores (2019).

Quadro 30. Autores mais produtivos na XVI edição (2015) - Encontro Nacional de Pesquisa em Ciência da Informação

\begin{tabular}{|l|r|}
\hline Nome & Quant. \\
\hline Rosali Fernandez de Souza & 4 \\
\hline Zeny Duarte de Miranda & 4 \\
\hline Angela Maria Grossi de Carvalho & 3 \\
\hline Asa Fujino & 3 \\
\hline Beatriz Valadares Cendon & 3 \\
\hline 19 & 3 \\
\hline 78 & 2 \\
\hline 389 & 1 \\
\hline Total Autores / Itens & $619 / 299$ \\
\hline
\end{tabular}

Fonte: Elaborado pelos autores (2019). 

RDBCI

Quadro 31. Autores mais produtivos na XVII edição (2016) - Encontro Nacional de Pesquisa em Ciência da Informação

\begin{tabular}{|l|r|}
\hline Nome & Quant. \\
\hline Zeny Duarte de Miranda & 6 \\
\hline Georgete Medleg Rodrigues & 5 \\
\hline Maria Aparecida Moura & 5 \\
\hline Moises Lima Dutra & 5 \\
\hline Renata Maria Abrantes Baracho Porto & 5 \\
\hline 15 & 4 \\
\hline 31 & 3 \\
\hline 87 & 2 \\
\hline 462 & 1 \\
\hline Total Autores / Itens & $\mathbf{8 1 8 ~ / ~} 371$ \\
\hline
\end{tabular}

Fonte: Elaborado pelos autores (2019).
RD Digital Journal of Library and Information Science

Quadro 32. Autores mais produtivos na XVIII edição (2017) - Encontro Nacional de Pesquisa em Ciência da Informação

\begin{tabular}{|l|r|}
\hline Nome & Quant. \\
\hline Isa Maria Freire & 6 \\
\hline Caio Saraiva Coneglian & 5 \\
\hline Carlos Candido de Almeida & 5 \\
\hline Gustavo Silva Saldanha & 5 \\
\hline leda Pelógia Martins Damian & 5 \\
\hline 6 & 5 \\
\hline 15 & 4 \\
\hline 31 & 3 \\
\hline 94 & 2 \\
\hline 508 & 1 \\
\hline Total Autores / Itens & $\mathbf{9 0 5 / 3 9 2}$ \\
\hline
\end{tabular}

Fonte: Elaborado pelos autores (2019).

Quadro 33. Autores mais produtivos na XIX edição (2018) - Encontro Nacional de Pesquisa em Ciência da Informação

\begin{tabular}{|l|r|}
\hline Nome & Quant. \\
\hline Leilah Santiago Bufrem & 7 \\
\hline Carlos Xavier de Azevedo Netto & 5 \\
\hline Gustavo Silva Saldanha & 5 \\
\hline Izabel França de Lima & 5 \\
\hline Luciana Ferreira da Costa & 5 \\
\hline 3 & 5 \\
\hline 20 & 4 \\
\hline 36 & 3 \\
\hline 123 & 2 \\
\hline 565 & 1 \\
\hline Total Autores / Itens & $\mathbf{1 0 4 1 / 4 4 4}$ \\
\hline
\end{tabular}

Fonte: Elaborado pelos autores (2019).

Observa-se do quadro 19 até o 33, o predomínio de autores entre as cinco posições como: Isa Maria Freire, presente na X, XI e XVII edição, Silvana Aparecida Borsette Gregório presente apenas na edição IX. O fato de estar entre os primeiros, no geral, e estar em apenas um grupo de trabalho (entre os mais produtivos) significa que o autor estuda em diversos GT, demonstrando um compartilhamento de conhecimento sobre os diversos participantes, é o caso da autora Isa Maria Freire. 


\section{RDBCI}

\section{Considerações Finais}

O estudo identificou que a produção científica em conjunto com a bibliometria, no contexto de um evento, congresso ou encontro, representa a essência da identificação do quantitativo de itens em que podem ser analisados e qual característica o presente encontro pode formar. Nesta perspectiva, o padrão de informações disponibilizadas ao leitor, representa a captura dos dados de uma maneira bem mais rápida, não necessitando trabalhar muito os dados.

De acordo com os levantamentos dos dados de pesquisa, foi possível observar que a partir do V edição (2003) há um padrão quanto aos grupos de trabalhos de cada edição, e que os estudos já realizados, focam em apenas um grupo específico para a realização da medição ou então em enfoque diferente do realizado, o que permite a diversidade de estudo para que cada grupo de trabalho representa.

Com a totalidade dos dados coletados, quanto a edição, grupo de trabalho, comunicação e autores, foi possível identificar que há várias formas de explorar a respectiva base, em especial a realização da contagem dos autores, que podem ser realizada de forma fracionada e direta, não explorada no estudo, o que permite desenvolver um comparativo independentemente da posição ocupada pelo autor nos itens este continua como sendo o autor de maior representatividade do evento, ou grupo de trabalho.

A pesquisa identificada com a utilização dos Encontros Nacional de Pesquisa em Ciência da Informação possibilita estrategicamente a constituição de um campo cientifico mais fortalecido, que possibilita a visualização de parâmetros quanto ao crescimento do evento, e medir, mapear a estrutura já realizada.

O estudo, entretanto, apresentou limitações quanto a não padronização dos quatros primeiros eventos, quanto a separação em sessão temática e por ordem alfabética.

A partir da coleta dos dados, adotando a utilização do software Excel, a pesquisa revelou a possibilidade do desenvolvimento de estudos mais aprofundado quanto que autor cita qual, a realização de uma rede de associação entre autores dos artigos, pois foi analisada a autoria de cada edição, grupo de trabalho e na totalidade. De outra forma, considerando as características da pesquisa, foi possível também identificar o crescimento em cada edição do evento.

No entanto, a pesquisa revelou que o fato de o autor estar no primeiro lugar, como o autor mais produtivo do evento das edições analisadas, não significa que este seja o mais produtivo por edição e também por grupo de trabalho. Também revelou, o quantitativo de autores em cada grupo de trabalho, edição, demonstrando que a área de ciência da informação está em constante crescimento. 


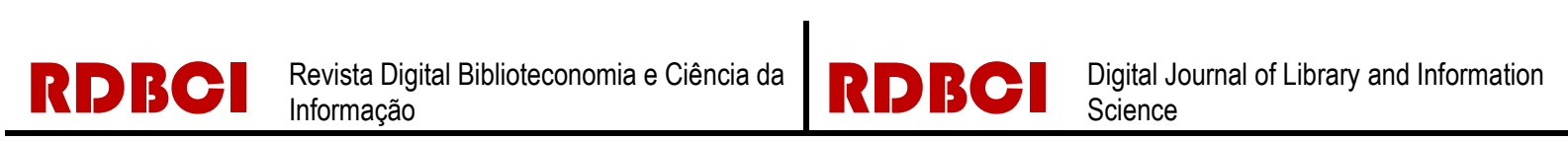

O papel da bibliometria, contudo, no contexto da análise é medir, diagnosticar, mapear e avaliar a informação quanto ao processo de produção. Entretanto, observou-se que esta forma de realização se obtém um foco em demonstrar o grupo de estudo e fortalecer o conhecimento do mesmo, quanto a que autor está estudando o respectivo assunto.

Para estudos futuros podem ser desenvolvidos como objetivo analisar a rede de autores do Enancib, utilização dos outros métodos de contagem. Além disso, pode-se realizar a comparação entre os métodos de contagem direta, fracionada e completa.

\section{Referências}

ANCIB, 2019. Disponível em: https://www.ancib.org.br/. Acesso em: 8 jul. 2019.

BEUREN, Ilse Maria; SILVA, Márcia Zanievicz da. Característica bibliométricas dos artigos sobre gestão hospitalar publicados em periódicos de alto impacto. Revista Cubana de Información en Ciencias de la Salud, v. 25, n. 1, p.36-65, 2014. Disponível em: http://www.acimed.sld.cu/index.php/acimed/article/view/274/380. Acesso em: 9 jul. 2019.

CASTRO, Italo Rodrigues; OLIVEIRA, Marlene. Análise bibliométrica da produção científica sobre as linguagens de indexação publicada nos anais de congresso do Enancib no período de 2012 a 2015. In: XVII Encontro Nacional de Pesquisa em Ciência da Informação, 2016, Salvador. Anais Eletrônico... Salvador: UFBA, 2016. Disponível em: http://www.ufpb.br/evento/index.php/enancib2016/enancib2016/paper/viewFile/3694/2240. Acesso em: 8 jul. 2019.

EVEDOVE, Paula Regina; FUJITA, Mariângela Spotti Lopes; TARTAROTTI, Roberta Cristina Dal'Evedove. A produção científica periódica na temática indexação. Análise bibliométrica no período de 2003 a 2012. In: XIV Encontro Nacional de Pesquisa em Ciência da Informação, 2013, Florianópolis. Anais Eletrônico... Florianopólis: UFSC, 2013. Disponível em: http://enancib.ibict.br/index.php/enancib/xivenancib/paper/viewFile/4358/3481. Acesso em: 8 jul. 2019.

ENANCIB, 2019. Disponível: http://enancib.ibict.br/index.php/enancib/index. Acesso em: 8 jul. 2019.

FIALHO, Janaina Ferreira; NUNES, Martha Suzana Cabral; CARVALHO, Telma de. A mediação da informação nos grupos de pesquisa e no GT 3 dos ENANCIB: espaços de comunicação científica em Ciência da Informação. Em questão, Porto Alegre, v. 23, n. 2 p.252-276, maio/ago., 2017. Disponível em:

https://seer.ufrgs.br/EmQuestao/article/view/66952. Acesso em: 8 jul. 2019. 


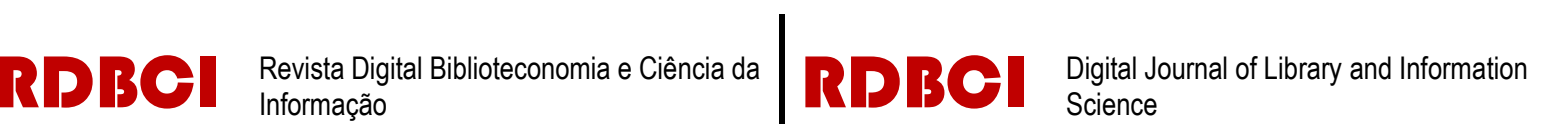

GRÁCIO, Maria Cláudia Cabrini; OLIVEIRA, Ely Francina Tannuri de Oliveira. GT7:

Produão e comunicação da informação em CT\&I. In: XVI Encontro Nacional de Pesquisa em Ciência da Informação, 2010, Rio de Janeiro. Anais Eletrônico... Rio de Janeiro: IBOCT/ UFRJ/ FIOCRUS/ UNIRIO, 2010. Disponível em:

http://enancib.ibict.br/index.php/enancib/xienancib/paper/viewFile/3537/2662. Acesso em: 10 jul. 2019.

GUEDES, Vania Lisboa Silveira. A bibliometria e a gestão e do conhecimento científico e tecnológico: uma revisão da literatura. Ponto de Acesso, Salvador, v. 6, n. 2, p.74109, ago, 2012.Disponível em:

http://www.portalseer.ufba.br/index.php/revistaici/article/view/5695/4591. Acesso em: 8 jul. 2019.

HILÁRIO, Carla Mara; GRÁCIO, Maria Cláudia Cabrini; WOLFRAM, Dietmar. Contribuição dos autores e ordem da autoria nos artigos do Journal of Informetrics (2016). In: XVIII Encontro Nacional de Pesquisa em Ciência da Informação, 18., 2017, Marília, SP.Anais [...]. Marília: UNESP/ANCIB, 2017. Disponível em:

http://enancib.marilia.unesp.br/index.php/xviiienancib/ENANCIB/paper/viewFile/372/498. Acesso em: 8 jul. 2019.

MONTENEGRO, Mano R.; ALVES, Venâncio A. Ferreira. Critérios de autoria e co-autoria em trabalhos científicos. Acta Botanica Brasilica, v.11, n.2, Dez. 1997. Disponível em: http://www.scielo.br/scielo.php?script=sci_arttext\&pid=S0102-33061997000200014. Acesso em: 8 jul. 2019.

MOREIRA; Walter; MORAES, Isabela Santana de. Análise bibliométrica em classificação no Brasil: um estudo nos anais do ENANCIB (2003-2014) In: ENCONTRO BRASILEIRO DE BIBLIOMETRIA E CIENTOMETRIA, 5., 2016, São Paulo. Anais Eletrônico... São Paulo: USP, 2016. Disponível em: http://www.brapci.inf.br/index.php/res/v/46036. Acesso em: 8 jul. 2019.

NORONHA, Daisy Pires et al. Comunicação em eventos da área da ciência da informação: contribuição dos docentes dos programas de pós-graduação. Revista eletrônica de

biblioteconomia e ciência da informação, Florianópolis, n.23, $1^{\circ} \mathrm{sem}$. 2007. Disponível em: https://periodicos.ufsc.br/index.php/eb/article/view/1518-2924.2007v12n23p171/402. Acesso em: 8 jul. 2019.

RABELLO, Rodrigo. Leituras sobre usuário e uso de informação na Ciência da Informação. Persprctivas em Ciência da Informação, Belo Horizonte, v.18, n. 4, dez.,2013. Disponível em: http://www.scielo.br/scielo.php?script=sci_arttext\&pid=S1413-99362013000400011. Acesso em: 8 jul. 2019.

ROSSIT, Rosana Aparecida Salvado; et. al.Grupo de pesquisa como espaço de aprendizagem em/sobre Educação Interprofissional (EIP). Interface, v. 22, supl. 2, 2018. Disponível em: http://www.scielo.br/pdf/icse/v22s2/1807-5762-icse-1807-576220170674.pdf. Acesso em: 9 jul. 2019. 
SANTOS, Andréa Pereida dos; REIS, Filipe; DUMONT, Lígia Maria Moreira. Práticas de leitura: estudo qualitativo e bibliométrico dos artigos publicados nos anais do encontro nacionais de pesquisa em ciência da informação - Enancib. In: XIX Encontro Nacional de Pesquisa em Ciência da Informação, 2018, Londrina. Anais Eletrônico... Londrina: UEL, 2018. Disponível em:

http://enancib.marilia.unesp.br/index.php/XIXENANCIB/xixenancib/paper/viewFile/1241/152 2. Acesso em: 8 jul. 2019.

TARTAROTTI, Roberta Cristina Dal' Evedove; FUJITA, Mariângela Spotti Lopes. Produção e colaboração científica em Organização e Representação do conhecimento: análise bibliométria do GT2 do ENANCIB no período de 2009 a 2014. Em questão, Porto Alegre, v. 22, n. 3 p.136-160, set./ dez., 2016. Disponível em: https://dialnet.unirioja.es/descarga/articulo/6141957.pdf. Acesso em: 8 jul. 2019.

URBIZAGASTEGUI, Ruben. A produtividade dos autores sobre a Lei de Lotka. Ciência da Informação, Brasília, v.37, n.2, p.87-102, maio/ago. 2008. Disponível em: http://www.scielo.br/pdf/ci/v37n2/a07v37n2.pdf. Acesso em: 8 jul. 2019.

YOUTIE, Jan; BORZEMAN, Barry. Social dynamics of research collaboration: norms, practices, and ethical issues in determining co-authorship rights. Scientometrics, Holanda, v. 101, n. 2, p.953-962, nov. 2014. Disponível em:

https://link.springer.com/article/10.1007/s11192-014-1391-7. Acesso em: 8 jul. 2019.

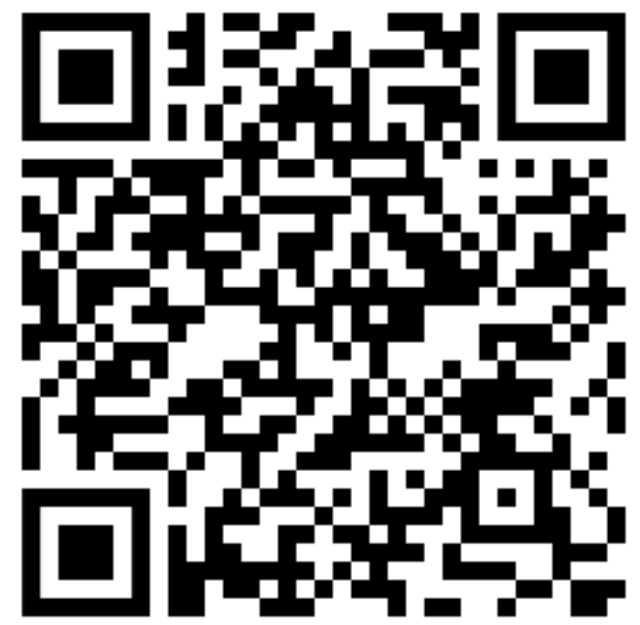

